\title{
ANÁLISE DE VIABILIDADE DOS CUSTOS PARA A REATIVAÇÃO DO TERMINAL DE CONCHAS NA HIDROVIA TIETÊ PARANÁ
}

\author{
Moacir Freitas Junior - Fatec Zona Sul/UNIP \\ bicimo@uol.com.br \\ Rodrigo Carlo Toloi - IFMT/UNIP \\ toloirodrigo@uol.com.br \\ João Gilberto Mendes dos Reis - UNIP \\ betomendesreis@msn.com
}

\section{Resumo}

O transporte de grãos da produção até seus locais de transformação e/ou exportação tem no transporte sua maior dificuldade na cadeia de suprimentos. Apresentando a estrutura atual da Hidrovia Tiete-Paraná e, caracterizando os elementos de um projeto hidroviário. Este artigo teve como objetivo avaliar os custos com a reativação do terminal hidroviário localizado na cidade de Conchas/SP, apresentando suas vantagens, desvantagens e sua viabilidade no tocante aos custos, quando comparado e somado às despesas de transbordo e operação que ocorrem a partir da utilização dos modais rodoviário e ferroviário hoje, buscando alternativas para minimizar o impacto dos valores nessa movimentação, além da verificação do valor a desembolsar pela reativação desse terminal hidroviário. Os resultados indicam que a utilização trecho da Hidrovia Tiete-Paraná que liga Pederneiras/SP Conchas/SP, permitirá além de uma significativa redução dos custos com o transporte, uma importante mitigação da emissão de GEE, que favoreceriam ao aumento da competitividade da produção brasileira.

Palavras-chave: Logística, Soja, Hidrovia, Custo. 


\begin{abstract}
The transport of grain from the production to its processing and export sites has in transportation its greatest difficulty in the supply chain. Presenting the current structure of the Tiete-Paraná Waterway, and characterizing the elements of a waterway project, this article aimed to evaluate the costs with the reactivation of the water terminal located in the city of Conchas / SP, presenting its advantages, disadvantages and its viability in the When compared and added to the transhipment and operation expenses that occur from the use of road and rail modalities today, seeking alternatives to minimize the impact of the values in this movement, in addition to verifying the amount to be paid for the reactivation of this waterway terminal. The results indicate that the use of the TieteParaná Waterway linking Pederneiras / SP - Conchas / SP, will allow a significant reduction in transportation costs and a substantial mitigation of GHG emissions, which would favour an increase in the competitiveness of production Brazilian.
\end{abstract}

Key Words: Logistics, Soybean, Waterway, Cost.

\title{
1 Introdução
}

O transporte hidroviário combina diferentes fatores e elementos, tais como os naturais, técnicos e os de organização, que inter-relacionados com o fator humano geram o aproveitamento desse sistema e a integração do espaço geográfico. Frente a essa temática, pela teoria das combinações geográficas de Choley (1964) é primordial que se considere o conjunto os cursos fluviais, os objetos presentes no espaço e as iniciativas da sociedade.

Costa (2001) em seu trabalho relata que todos os países que possuem grandes dimensões, como o Brasil, refletem um problema de transporte, pois é ele que obtém a integração e o crescimento das regiões mais afastadas. Dentre os meios disponíveis, o que mais se destaca, com características realmente polivalentes é a hidrovia.

Assim, a readequação das infraestruturas oferecidas, buscando otimizar os recursos materiais nas operações de gestão e logística são hoje uma necessidade, pois a dependência do transporte rodoviário em relação aos demais modais, encarece de sobremaneira os custos da cadeia de suprimentos. 
No Brasil grande parte da produção agrícola nacional está voltada ao mercado externo, criando um superávit através das commodities e envolvendo altos volumes de carga. Neste contexto, o modal hidroviário aparece como modal de transporte ideal a ser expandido (FREITAS et al., 2015).

Grande produtor e exportador de commodities, o Brasil destaca-se quanto ao volume de produção de grãos e, com a grande necessidade de escoar tais produtos principalmente a soja, justificando-se assim o investimento na ampliação do sistema hidroviário, possibilitando assim a redução dos custos de transporte, principalmente de grãos e obtendo ganhos econômicos e ambientais.

O transporte hidroviário, mesmo necessitando de intermodalidade para o seu melhor funcionamento e apresentando uma baixa velocidade no transporte, oferece grandes vantagens em relação aos demais modais de transporte, tanto no ponto de vista econômico (apresentando baixo custo do frete de transporte e grande capacidade de cargas), quanto no ponto de vista de em sustentabilidade (pois é um sistema menos poluente).

Além dos fatores econômicos e ambiental do sistema, é necessário considerar outras variáveis que apontam para as vantagens na utilização do modal hidroviário. A Tabela 1 apresenta variáveis que sinalizam para uma maior viabilidade do modal.

Tabela 1. Vantagens na utilização do modal hidroviário.

\begin{tabular}{ll}
\hline \multicolumn{1}{c}{ Maior } & \multicolumn{1}{c}{ Menor } \\
\hline - Eficiência energética & - Consumo de combustível \\
- Capacidade em concentrar cargas & - Emissão de poluentes \\
- Durabilidade da infraestrutura & - Congestionamento tráfego \\
- Período de utilização dos veículos & - Custo da infraestrutura \\
- Durabilidade dos equipamentos & - Número de acidentes \\
- Segurança da carga & - Custo de operação \\
- Controle fiscal & - Volume de ruído \\
\hline
\end{tabular}

Fonte: Freitas et al, 2016 
O Brasil, embora possua uma extensa rede hidrográfica, apresenta um uso inexpressivo do sistema hidroviário comparado com a Europa e os Estados Unidos, Tabela 2.

Tabela 2: Comparação do transporte Hidroviário: Brasil x EU x União Europeia

\begin{tabular}{lccc}
\hline \multicolumn{1}{c}{ Aspecto } & União Europeia & Estados Unidos & Brasil \\
\hline Tamanho em km² & 10.180 .000 & 9.826 .675 & 8.514 .877 \\
Extensão das hidrovias em Km & 51.668 & 41.009 & 41.994 \\
Extensão das hidrovias & UE25: 37.200 & & \\
navegáveis (utilizadas para & UE27 2008: & 19.312 & 20.956 \\
comércio) em Km & 40.929 & & Mississipi: \\
Carga anual transportada pelo & milhões de & 483 milhões & 25 \\
THI & toneladas & de & milhões de \\
Tamanho da frota quantidade & & toneladas & toneladas \\
de embarcações) & 17.679 & 40.512 & 857 \\
\hline
\end{tabular}

Adaptado de Ministério dos Transportes (2016).

A Tabela 2 demonstra que o Brasil tem potencial e malha hidroviária superior ao dos Estados Unidos, mas concentra quase $60 \%$ da sua matriz de transporte no modal rodoviário (POMPERMAYER, CAMPOS NETO e DE PAULO, 2014).

Como exemplo, a Hidrovia Tietê-Paraná, encontra-se subutilizada e com infraestrutura ainda incipiente, necessitando de investimentos para que seu funcionamento possa ser otimizado, promovendo sobremaneira o transporte de cargas. Neste sentido este estudo, tem como objetivo identificar os impactos no transporte de grãos obtidos com a ativação do terminal e da Hidrovia Tietê-Paraná ligando a linha férrea na cidade de Conchas/SP. 
A partir do objetivo principal surgem os objetivos secundários que orientaram a realização deste estudo. Assim os objetivos específicos propostos são:

- Apresentar o cenário atual da logística de transporte pela Hidrovia Tietê-Paraná;

- Verificar quais são as principais mercadorias transportadas pela Hidrovia TieteParaná;

- Estimar o custo para a reativação do terminal de Conchas;

- Estimar o impacto da reativação do trecho da Hidrovia, no transporte de grãos.

\section{Metodologia}

Este trabalho consiste em uma pesquisa exploratória, com característica descritiva que pretende realizar um levantamento dos impactos gerados pela reativação do Terminal Pederneiras/SP - Conchas/SP, simulando uma forma alternativa para o escoamento da produção de grãos até o porto de Santos.

O estudo ainda consistiu na realização de uma pesquisa bibliográfica, para fosse possível identificar:

a) O cenário atual da logística de transporte pela Hidrovia Tietê-Paraná;

b) As principais mercadorias transportadas e os respectivos volumes movimentados

c) Por fim, descreveu os impactos gerados no transporte com a reativação do trecho da Hidrovia Tiete-Paraná que liga Pederneiras/SP - Conchas/SP.

\section{Hidrovias Brasileiras}

O Brasil possui grande potencial hidroviário, a ser melhor explorado. A Tabela 3, demonstra que, as hidrovias utilizadas para o transporte de cargas no País, tem sua utilização reduzida, podendo ser ampliada a sua utilização. Segundo o Ministério dos Transportes (2016), as principais hidrovias no Brasil são: São Francisco, Madeira, Paraná/Tietê, Tocantins/Araguaia e Paraguai/Paraná. 
Tabela 3 - Rede Hidroviária brasileira

Fonte: Oliva (2016).

\begin{tabular}{|c|c|c|c|c|c|}
\hline \multirow{3}{*}{ Bacia } & \multirow{3}{*}{ Estados } & \multicolumn{3}{|c|}{ Extensão Aproximada em Km } & \multirow{3}{*}{ Rios } \\
\hline & & \multicolumn{3}{|c|}{ Potencial } & \\
\hline & & Navegável & Potencial & Total & \\
\hline Amazônica & $\begin{array}{l}\text { AM, PA } \\
\text { AC, RO, } \\
\text { RR e AP }\end{array}$ & $18.300,00$ & 723,50 & $19.023,5$ & $\begin{array}{c}\text { Amazonas, Solimões, } \\
\text { Negro, Branco, Madeira, } \\
\text { Purus, Juruá, Tapajós, } \\
\text { Teles, Pires e Guaporé }\end{array}$ \\
\hline Nordeste & MA e PI & $1.740,00$ & $2.975,00$ & $4.715,0$ & $\begin{array}{c}\text { Meariam, Pindaré, } \\
\text { Itapecuru, } \\
\text { Parnaíba e Balsas. }\end{array}$ \\
\hline $\begin{array}{l}\text { Tocantins/ } \\
\text { Araguaia }\end{array}$ & $\begin{array}{l}\text { TO, MA e } \\
\text { GO }\end{array}$ & $2.200,00$ & $1.300,00$ & $3.500,0$ & $\begin{array}{l}\text { Tocantins, } \\
\text { Araguaia e das } \\
\text { Mortes. }\end{array}$ \\
\hline $\begin{array}{l}\text { São } \\
\text { Francisco }\end{array}$ & $\begin{array}{l}\text { MG, BA, } \\
\text { PE e SE }\end{array}$ & $1.400,00$ & $2.700,00$ & $4.100,0$ & $\begin{array}{l}\text { São Francisco, } \\
\text { Grande e Corrente. }\end{array}$ \\
\hline Leste & $\begin{array}{l}\text { MG, ES e } \\
\text { RJ }\end{array}$ & - & $1.094,00$ & $1.094,0$ & $\begin{array}{l}\text { Doce, Paraíba do Sul } \\
\text { e } \\
\text { Jequitinhonha. }\end{array}$ \\
\hline Paraná & $\begin{array}{l}\text { SP, PR e } \\
\text { SC }\end{array}$ & $1.900,00$ & $2.900,00$ & $4.800,0$ & $\begin{array}{l}\text { Paraná, Tietê, } \\
\text { Paranaíba, } \\
\text { Grande, Ivaí e } \\
\text { Ivinhema. }\end{array}$ \\
\hline Sudeste & RS & 600,00 & 700,00 & $1.300,0$ & $\begin{array}{c}\text { Jacuí, Taquari, Lagoa } \\
\text { dos Patos e Lagoa Mirim. }\end{array}$ \\
\hline Uruguai & $\mathrm{RS}$ e $\mathrm{SC}$ & - & $1.200,00$ & $1.200,0$ & Uruguai e Ibicuí. \\
\hline
\end{tabular}


A Hidrovia São Francisco, tem potencial para expandir em 193\% a sua extensão saindo dos atuais $1.400 \mathrm{~km}$ para $4.100 \mathrm{~km}$. Essa expansão poderia melhorar a competitividade no escoamento da produção dos Estados de Minas Gerais, Bahia, Pernambuco e Sergipe.

A Hidrovia Nordeste que atualmente possui $1.740 \mathrm{~km}$ navegais poderia expandir a sua extensão em $171 \%$ e assim chegando aos $4.715 \mathrm{~km}$, contribuindo com o escoamento da produção dos Estados do Piauí e Maranhão, atualmente considerados uma das últimas fronteiras agrícolas.

A Hidrovia Tietê-Paraná, também possui grande potencial ainda a ser explorado, podendo sair dos atuais $1.900 \mathrm{~km}$ e atingir os $4.800 \mathrm{~km}$, um acréscimo de $153 \%$.

A Hidrovia Tocantins-Araguaia pertence ao corredor Centro Norte e é divindade em quatro tramo, Peixe à Marabá, Marabá à foz do Tocantins, Baliza à Conceição do Araguaia deste último à foz do Araguaia perfazendo um total de $1021 \mathrm{~km}$.

A Hidrovia Paraguai-Paraná tem 1031 km. Começando no munícipio de Cáceres/MT segue até o Uruguai na cidade de Nueva Palmira. A Figura 1, apresenta no mapa brasileiro essas hidrovias.

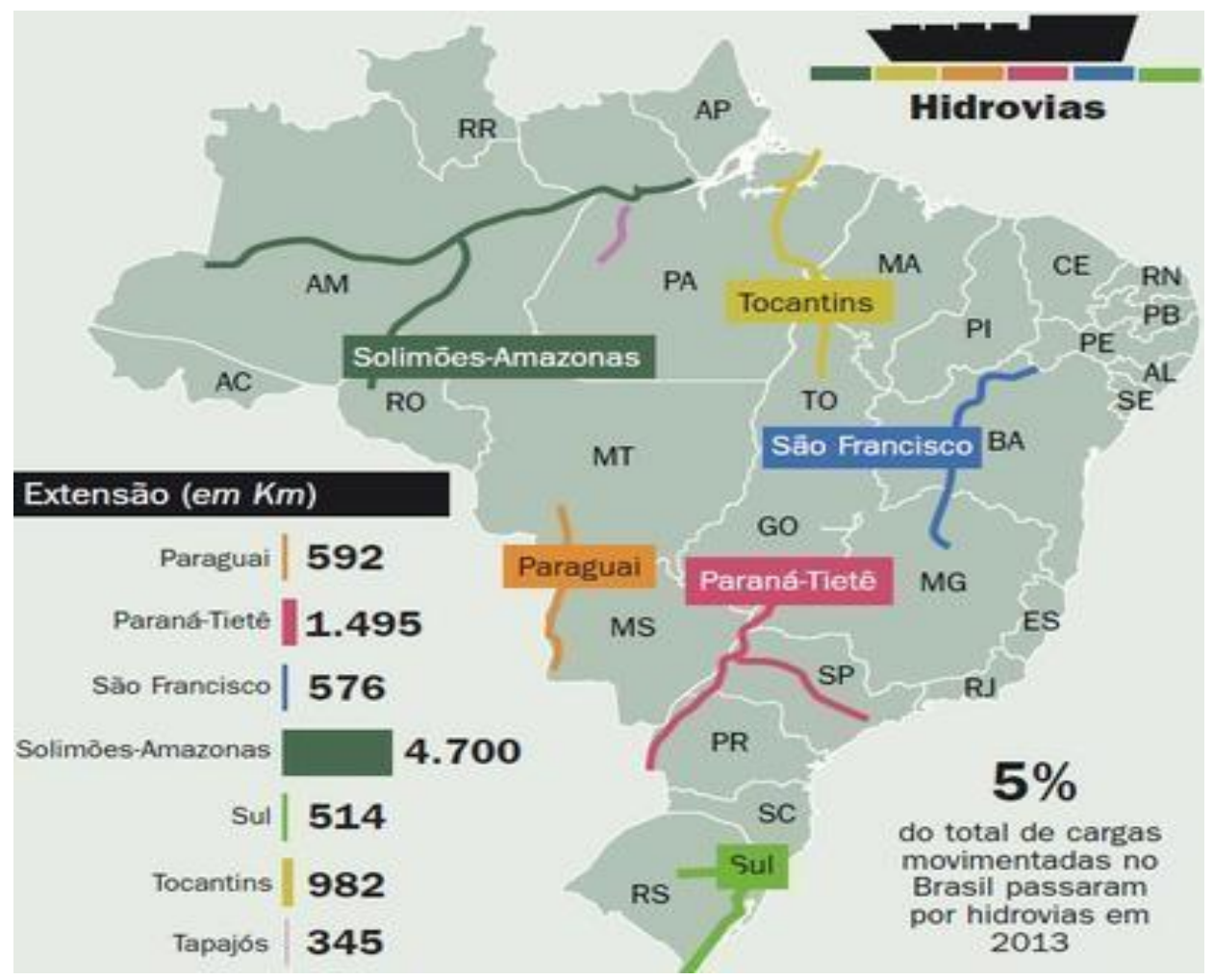

Figura 1. Mapa Hidroviário e Extensão das Hidrovias brasileiras. Fonte: Santos (2014) 
As condições das Hidrovias brasileiras são comuns, estando distante do seu melhor aproveitamento, sendo necessário a realização de investimentos. Freitas et.al. (2016) afirma que sua utilização para escoamento de cargas a longas distâncias é mínima no Brasil. Isso deve-se principalmente pelas ações governamentais que priorizaram a construção de rodovias a partir de 1956 fazendo que nossa matriz de transporte hoje seja representada em $60 \%$ pelo transporte rodoviário (MENDONÇA, 2006; POMPERMAYER, CAMPOS NETO e DE PAULO, 2014).

\section{RESULTADOS E DISCUSSÃO}

\section{Cenário atual da logística de transporte pela Hidrovia Tietê-Paraná;}

O sistema da Hidrovia Tietê-Paraná além de possuir 2.400 quilômetros de vias navegáveis entre as cidades paulistas de Conchas e Piracicaba (SP), permite a interligação dos estados de Goiás com Minas Gerais; Mato Grosso do Sul com o Paraná e o Paraguai. Possui ainda instalada no seu leito seis usinas hidrelétricas e oito eclusas no rio Tietê, quatro usinas e duas eclusas no rio Paraná, 23 pontes, 19 estaleiros e 30 terminais intermodais privados (recepção e transformação, armazenagem e transferência), conforme dados da Agência Nacional de Transportes Aquaviários (ANTAQ, 2013).

Esta infraestrutura mostra-se como alternativa econômica para o transporte de cargas, além de também propiciando o reordenamento da matriz de transportes da região Centro-Oeste do estado de São Paulo, impulsionando o desenvolvimento regional de cidades como Barra Bonita e Pederneiras (TEIXEIRA, 2010).

Os terminais privados de Pederneiras/SP, Anhembi/SP e Santa Maria da Serra/SP destacam-se na distribuição de grãos e farelos criando novos empregos e renda para a região, conforme Tabela 4. 
Tabela 4. Transporte de Soja em Toneladas nos Principais Terminais

\begin{tabular}{lrrrr}
\hline \multicolumn{1}{c}{ TERMINAL } & \multicolumn{1}{c}{$\mathbf{2 0 1 1}$} & \multicolumn{1}{c}{$\mathbf{2 0 1 2}$} & \multicolumn{1}{c}{$\mathbf{2 0 1 3}$} & \multicolumn{1}{c}{$\mathbf{2 0 1 4}$} \\
\hline PEDERNEIRAS & 899.427 & 910.535 & 821.172 & 301.080 \\
ANHEMBI & 174.066 & 57.144 & 247.726 & 110.230 \\
SANTA MARIA DA SERRA & 94.724 & 92.047 & 95.963 & 80.687 \\
TOTAL & $\underline{1.168 .217}$ & $\underline{1.059 .726}$ & $\underline{1.164 .861}$ & $\underline{491.997}$ \\
\hline
\end{tabular}

Fonte: Adaptado de ANTAQ (2015)

A redução acentuada no transporte de soja por meio da hidrovia, em 2014, relaciona-se com às condições climáticas da região sudeste. A falta de chuvas contribuiu para o baixo nível de profundidade da via, causando restrições a navegação.

\section{Principais mercadorias transportadas pela Hidrovia Tiete Paraná;}

A Hidrovia Tietê-Paraná participa de forma significativa no transporte de produtos do agronegócio brasileiro, o Quadro 1, descreve os principais produtos que foram movimentados pela Hidrovia Tietê-Paraná no período de 2012 a 2015.

Quadro 1: Principais Produtos Movimentados pela Hidrovia Tietê-Paraná

\begin{tabular}{|c|c|c|c|c|c|c|}
\hline \multirow{2}{*}{ PRODUTOS } & \multicolumn{5}{|c|}{ MOVIMENTAÇÃO (toneladas) } & \multirow[b]{2}{*}{$(\%)$} \\
\hline & 2012 & 2013 & 2014 & $2015\left(^{\star}\right)$ & TOTAL & \\
\hline CANA DE AÇÚCAR & 902.118 & 767.557 & 899.184 & 960.281 & 3.529 .140 & 16,3 \\
\hline SOJA & 1.059 .726 & 1.164 .861 & 491.997 & - & 2.716 .584 & 12,5 \\
\hline FARELO DE SOJA & 374.256 & 300.056 & 62.402 & - & 736.714 & 3,4 \\
\hline CELULOSE & - & 200.696 & 72.423 & - & 273.119 & 1,3 \\
\hline MADEIRA & - & 462.349 & 121.298 & - & 583.647 & 2,7 \\
\hline MILHO & 802.210 & 956.811 & - & - & 1.759 .021 & 8,1 \\
\hline AREIA & 1.181 .601 & 1.148 .778 & 1.233 .213 & 1.075 .155 & 4.638 .747 & 21,4 \\
\hline TOTAL TIETÊ & 4.319 .911 & 5.001 .108 & 2.880 .517 & 2.035 .436 & 14.236 .972 & 65,7 \\
\hline AREIA & 1.327 .077 & 866.928 & 1.254 .701 & 1.842 .400 & 5.291 .106 & 24,4 \\
\hline SEMENTES & 2.051 & 469 & 3.497 & 400 & 6.417 & 0,0 \\
\hline PNEU/MÁQUINAS & 3.569 & 6.100 & 4.979 & 6.224 & 20.872 & 0,1 \\
\hline
\end{tabular}




\begin{tabular}{|c|c|c|c|c|c|c|}
\hline CALCÁRIO/ADUBO & 103.280 & 78.917 & 78.953 & 65.464 & 326.614 & 1,5 \\
\hline SOJA & 35.141 & 21.209 & 59.093 & 21.467 & 136.910 & 0,6 \\
\hline MILHO & 313.584 & 286.033 & 331.477 & 280.184 & 1.211 .278 & 5,6 \\
\hline TRIGO & 56.156 & - & 21.500 & - & 77.656 & 0,4 \\
\hline MADEIRA/CARVÃO & - & - & - & 37.650 & 37.650 & 0,2 \\
\hline MANDIOCA & 15.175 & - & 6.079 & 11.645 & 32.899 & 0,2 \\
\hline CANA DE AÇÚCAR & - & - & - & 260.000 & 260.000 & 1,2 \\
\hline OUTROS & 5.152 & 9.837 & 4.333 & 14.108 & 33.430 & 0,2 \\
\hline TOTAL PARANÁ & $\mathbf{1 . 8 6 1 . 1 8 4}$ & $\mathbf{1 . 2 6 9 . 4 9 3}$ & $\mathbf{2 . 5 3 9 . 5 4 2}$ & $\mathbf{7 . 4 3 4 . 8 3 1}$ & $\mathbf{3 4 , 3} \%$ & \\
\hline TOTAL GERAL & $\mathbf{6 . 1 8 1 . 0 9 4}$ & $\begin{array}{l}\mathbf{6 . 2 7 0 . 6 0 1} \\
\mathbf{4 . 6 4 5 . 1 2 9}\end{array}$ & $\mathbf{4 . 5 7 4 . 9 7 8}$ & $\mathbf{2 1 . 6 7 1 . 8 0 2}$ & $\mathbf{1 0 0 , 0 \%}$ & \\
\hline
\end{tabular}

*valores menores de carga devido estiagem que paralisou grande parte da rede Fonte: adaptado de (DHSP, 2016)

Dentre os produtos que foram transportados pela Hidrovia, excluem-se a areia, pneus/maquinários e calcário/adubos, que não são produtos oriundos do agronegócio. Os demais produtos movimentados na hidrovia são produzidos pela agropecuária brasileira, e tem como destino principal o mercado externo.

A soja e seus derivados ocupam posição de destaque entre os produtos que são transportados via Hidrovia Tietê-Paraná, sendo responsável, somando-se os dois tramo, por $16,6 \%$ de toda a movimentação existente, ficando atrás apenas da Cana de Açúcar que é responsável por 17,5\% da movimentação (FELIPE JUNIOR; SILVEIRA, 2009).

\section{Breve Histórico do Terminal de Conchas}

Construído em 1999, o terminal tem capacidade de receber 500 toneladas de carga por hora, que após descarregadas, barcaças são carregadas com fertilizantes e calcário para o retorno (FELIPE JUNIOR; SILVEIRA, 2009).

Pertencente a Companhia Nacional de Armazéns Gerais Alfandegados - CNAGA, tem 214 mil m², um píer de 12×10, 4 dolfins entre 24 e 72 metros, dois silos com capacidade de 3.300 tons. Cada um, um silo pulmão de 80 tons, o acesso via modal rodoviário é feito por uma via asfaltada de $22 \mathrm{~km}$. 
Apesar da necessidade da retificação de algumas curvas no trajeto, por um estudo da CESP - Companhia Energética de São Paulo, 95\% da frota pode circular normalmente. De toda carga transportada na Hidrovia Tiete-Paraná, 39\% é representado pela soja, quando navegável, sua estrutura hoje gera 1,6 mil empregos (DHSP, 2016).

Segundo o DHSP (2016), o porto de Conchas não opera por falta de demanda, uma vez que é possível navegar nesse trecho do Rio Tietê com uma barcaça, único empecilho para os 5\% da frota, seria o desmembramento dos comboios, gerando uma operação que tem a duração de três horas, o que mesmo não operacional a termo, poderiam circular nessa condição. A retificação do canal navegável até Conchas é objeto de licenciamento ambiental.

O Porto de Conchas desativado, não que este seja o motivo, pois já existe licença ambiental para sua operação, passou a ser colocado pelos ambientalistas como um dos motivos para a oposição ao projeto de ampliação da hidrovia no Rio Piracicaba. Com a sua utilização, teria-se um acréscimo em produtividade da ordem de 192.000 toneladas de movimentação de grãos a mais no ano (FELIPE JUNIOR; SILVEIRA, 2009).

\section{Custo para Reativação e Manutenção do Terminal de Conchas}

Para efeito de análise, o que difere na tomada de decisão na escolha pela implantação de um modal é o, custo de implantação e manutenção e o tempo de vida útil que cada modal apresenta. A Tabela 5 descreve os custos para a construção, manutenção e a vida útil dos principais modais utilizados no Brasil. 
Tabela 5: Comparativo de custos de Infraestrutura/Construção dos modais.

\begin{tabular}{lccc}
\hline Custo de Implantação/Custo da Vida Útil & HIDRO & FERRO & RODO \\
\hline Média de Construção Via (US\$/Km) & 34000 & 1400000 & 440000 \\
Custo de Manutenção da Via & BAIXO & ALTO & ALTO \\
Custo da Vida Útil da Via & ALTA & ALTA & BAIXA \\
Vida Útil Equipamentos/Veículos (Anos) & 50 & 30 & 10 \\
*\% Menor Em Relação Ao Hidroviário & $X$ & $>40 \%$ & $>80 \%$ \\
\hline
\end{tabular}

Fonte: Ministério dos Transportes (1997)

Diante da observação da Tabela 5 nota-se que o modal que apresenta maior vantagem é o hidroviário porque levando em consideração o custo para manutenção em US $\$ / \mathrm{km}$, o modal hidroviário é 41 vezes menor que o ferroviário, e 13 vezes menor que o rodoviário. Além de ter sua vida útil $40 \%$ maior que o modal ferroviário, e $80 \%$ maior quando comparado ao rodoviário.

Os custos ligados aos veículos e ao combustível sofrerão pouca influência do volume a ser transportado enquanto os custos de infraestrutura (implantação e manutenção) serão rateados pelo volume transportado. A lógica que aparece nesse caso é a de que, quanto maior for o volume a ser transportado, menor deverá ser o custo unitário (por tonelada) relacionado à infraestrutura.

Considerando somente os custos operacionais com veículos, combustível e transferências de carga, não levando em conta aqueles associados à implantação da infraestrutura viária, o custo da hidrovia fica em torno de $R \$ 16 /$ tonelada, um pouco mais elevado que a ferrovia (POMPERMAYER; CAMPOS NETO; DE PAULA, 2014).

A Figura 2 mostra a situação de menor custo do transporte hidroviário em rios naturalmente navegáveis. Existem rios que carecem de algum ajuste de seus leitos para permitir seu maior aproveitamento para a movimentação em larga escala. Quando o volume de intervenções é maior, as hidrovias têm o custo próximo ao das ferrovias. 


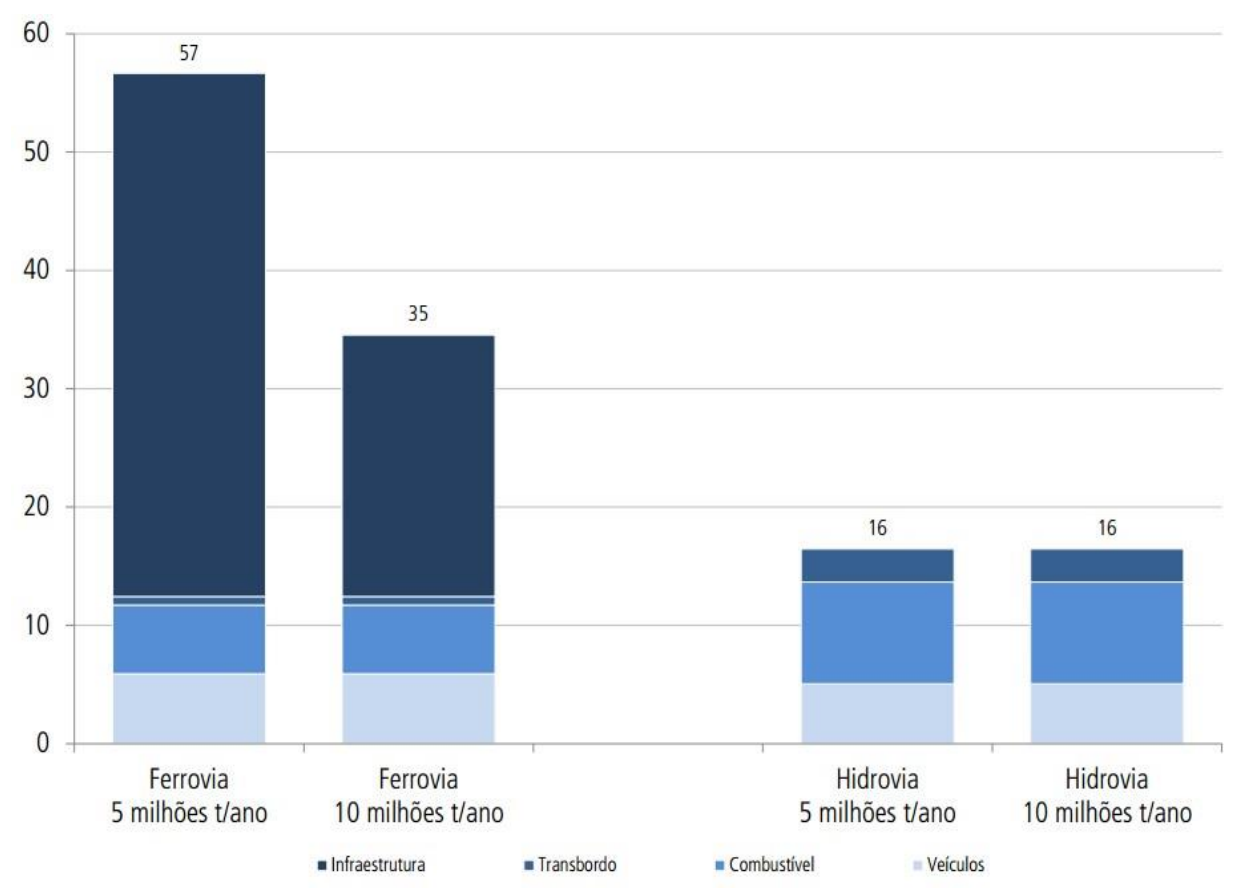

Figura 2. Comparação de custos entre ferrovia e rio navegável. Fonte: Pompermayer; Campos Neto; De Paula (2014)

\section{Impacto Ambiental Gerado com a Reativação do Trecho da Hidrovia Tiete-Paraná Que Liga Pederneiras/SP - Conchas/SP}

A matriz logística brasileira é extremamente dependente do transporte rodoviário, fato que pode ser considerado um problema a ser resolvido não só do ponto de vista econômico, mas também pela ótica do consumo energético e dos impactos ambientais.

Entre todos os setores que emitem $\mathrm{CO}_{2}$, o setor de transportes é o que está crescendo mais rapidamente, representando de 22 a $24 \%$ das emissões globais dos gases de efeito estufa de fontes de combustíveis fósseis (JOÃO \& JOÃO, 2008).

Por apresentar um consumo energético acima da média mundial o setor de transportes brasileiro aparece como um problema no que se refere às emissões de Gases de Efeito Estufa - GEE sobretudo de seu principal gás, o Dióxido de Carbono $\left(\mathrm{CO}_{2}\right)$ (ANDRADE, 2011).

Neste sentido utilização do trecho da Hidrovia Tiete-Paraná que liga Pederneiras/SP - Conchas/SP possibilitaria uma redução na utilização do modal rodoviário, e consequentemente uma mitigação na emissão de GEE. Com maior 
capacidade de carga por unidade de transporte, o modal hidroviário também apresenta vantagens conforme a Tabela 6.

Tabela 6. Quantidade de Veículos que seriam utilizados para o Transporte do Volume movimentado na Hidrovia Tietê-Paraná

\begin{tabular}{cccc}
\hline Modal & $\begin{array}{c}\text { Volume } \\
\text { Transportado*** } \\
\text { (ton) }\end{array}$ & $\begin{array}{c}\text { Capacidade de } \\
\text { Carga do Modal } \\
\text { (ton) }\end{array}$ & $\begin{array}{c}\text { Quantidade de } \\
\text { Veículos } \\
\text { Utilizados (Un) }\end{array}$ \\
\hline${ }^{*}$ Hidroviário & 21.671 .802 & 6.000 & 3.612 \\
${ }^{* \star}$ Ferroviário & 21.671 .802 & 70 & 309.597 \\
${ }^{* \star \star R o d o v i a ́ r i o ~}$ & 21.671 .802 & 35 & 619.194 \\
\hline
\end{tabular}

* Composição de um comboio com 4 chatas e um empurrador; ** vagões com capacidade de carga de 70 toneladas; ${ }^{* *}$ Carretas Bi-trem graneleiras, com capacidade de 35 toneladas.

*** no tópico volume transportado foi considerada toda a movimentação entre os anos de 2012 a 2015 Fonte: Adaptado de Perrupato (2009).

A Tabela 6 indica que o volume de carga movimentada pela Hidrovia TietêParaná de 2012 a 2015 foi de 21.671.802 toneladas. Para transportar esse volume, pelo modal hidroviário foram necessários 3.612 comboios de 4 chatas e um empurrador.

Caso o volume fosse transportado pelo modal ferroviário, seriam necessários 309.597 vagões de capacidade de 70 toneladas, e ainda caso o volume fosse transportado pelo modal rodoviário seriam utilizados 619.194 caminhões Bi-trem com capacidade de 35 toneladas. Essa redução no número de veículos utilizados para transporte de cargas reflete diretamente na economia de combustível e na redução na emissão de GEE.

O modal hidroviário apresenta na sua estrutura geral um transporte sustentável de cargas uma vez que por exemplo no modal rodoviário, são transportadas por grande quantidade de caminhões nas cidades elevando os níveis de congestionamento, provocando lentidão nas viagens, aumento no número de acidentes e na poluição 
ambiental. A utilização desse modal faz com seja emitido muitos gases poluentes, além de gerar ruído e calor (RAMOS et al., 2014).

A Tabela 7 mostra que se utilizando do modal hidroviário tem-se uma redução de $170 \%$ na emissão de $\mathrm{CO}^{2}$ por KG/1000 TKU quando comparado ao ferroviário e de $580 \%$ no caso do transporte rodoviário.

Tabela 7. Transporte Sustentável de Cargas.

\begin{tabular}{lcc}
\hline MODAL / CONSUMO & $\begin{array}{c}\text { COMBUSTÍVEL } \\
\text { L/1000 TKU }\end{array}$ & $\begin{array}{c}\text { EMISSÃO } \text { CO }^{{ }^{* *}} \\
\mathrm{KG} / 1000 \text { TKU }\end{array}$ \\
\hline HIDROVIÁRIO & 5 & 20 \\
FERROVIÁRIO & 10 & 34 \\
RODOVIÁRIO & 96 & 116 \\
\hline
\end{tabular}

Fonte: Adaptado de Ramos et al., (2014).

${ }^{*}$ DOT/Maritime e TCL

Reduzir a emissão de poluentes na utilização de recursos, melhora o desempenho das atividades, diminui os custos operacionais, otimizando procedimentos que visam melhorar a qualidade de vida dos funcionários além de divulgar a empresa que poderá agregar tais atitudes quando da divulgação pela empresa num programa mercadológico.

Com a utilização efetiva do transporte hidroviário, as empresas tornam os processos mais sustentáveis, valorizando todos as pessoas envolvidas no processo (acionistas, colaboradores, clientes e a própria comunidade).

Visão ambiental social e moderna, transforma-se em fator determinante para 0 sucesso das empresas, pois estimula a capacidade de interação e integração com a sociedade e com o meio ambiente, aumentando a competitividade.

\section{Impacto Econômico Gerados com a Reativação do Trecho da Hidrovia Tiete- Paraná que liga Pederneiras/SP - Conchas/SP}

Considerando o impacto econômico gerado pela utilização de outros modais no trajeto considerado, é percebida a grande vantagem da utilização do hidroviário que 
representa respectivamente um custo $700 \%$ menor quando utilizado o ferroviário e $1100 \%$ se trabalhado no modal rodoviário, a Tabela 8 mostra essa diferença apresentando os valores considerados para um custo unitário do transporte de uma tonelada por $\mathrm{km}$.

Tabela 8. Custo do transporte de Acordo com o Modais disponíveis

\begin{tabular}{|c|c|c|c|c|}
\hline Modal & $\begin{array}{c}\text { Volume } \\
\text { Transportado*** } \\
\text { (ton) }\end{array}$ & $\begin{array}{c}\text { Distância } \\
\text { Percorrida } \\
\mathbf{( k m )}\end{array}$ & $\begin{array}{c}\text { Custo } \\
\text { Unitário } \\
\mathbf{( R \$ / t o n / k m )}\end{array}$ & $\begin{array}{c}\text { Custo Total de } \\
\text { Transporte }\end{array}$ \\
\hline Hidroviário & 21.671 .802 & 110 & $\mathrm{R} \$ 0,01$ & $\mathrm{R} \$ 23.838 .982,20$ \\
\hline Ferroviário & 21.671 .802 & 110 & $\mathrm{R} \$ 0,07$ & $\mathrm{R} \$ 166.872 .875,40$ \\
\hline Rodoviário & 21.671 .802 & 110 & $\mathrm{R} \$ 0,11$ & $\mathrm{R} \$ 262.228 .804,20$ \\
\hline
\end{tabular}

*** no tópico volume transportado considerada toda a movimentação entre os anos de $2012 / 2015$

Fonte: Adaptado de Reis et al. (2015)

De acordo com a Tabela 8 a utilização do trecho da Hidrovia Tiete-Paraná que liga Pederneiras/SP - Conchas/SP, que é equivalente a 110 quilômetros possibilitaria um ganho de competitividade significativo, devido especialmente a redução no custo com o transporte, uma vez que as commodities brasileiras que são exportadas perdem competitividade assim que saem da porteira das fazendas (OMETTO, 2006;.TOLOI et al., 2016).

\section{Considerações Finais}

Este estudo possibilitou identificar quais são os principais produtos e os respectivos volumes movimentados pela Hidrovia Tietê-Paraná. Dentre os principais produtos estão as commodities soja e o milho, produtos de baixo valor agregado que representam metade do volume trabalhado nesta via.

A ativação do Terminal de Conchas, não demandaria maiores custos uma vez que já está pronto e não dependerá de nenhuma intervenção mais efetiva, ter-se-ia um 
ganho de volume representado por 500 toneladas/hora/dia de carga a mais movimentada na Hidrovia, proporcionando um volume total 80.000 toneladas/mês.

Com isso seria reduzido o volume, que atualmente é direcionado ao modal rodoviário, reduzindo os custos além de minimizar os problemas com o meio ambiente pela baixa geração de partículas de $\mathrm{CO}_{2}$, eliminando-se também os custos ocultos como por exemplo, com o tempo de espera dos caminhões para descarga no Porto de Santos/SP.

Desse modo a utilização da hidrovia poderia representar uma importante redução dos custos de transporte e aumento da competitividade da produção de grãos brasileira frente ao mercado internacional.

Por fim, as evidencias aqui levantadas, sugerem que as vantagens da utilização do trecho da Hidrovia Tiete-Paraná que liga Pederneiras/SP - Conchas/SP, possibilitaria maior capacidade de carga, uma redução no número de veículos em transito, ganho de eficiência do uso energético para movimentação de cargas e consequentemente aumento na competitividade da produção nacional frente ao mercado externo. 


\section{Referências Bibliográficas}

ANDRADE, A. L. C.; MATTEI, L. Consumo Energético e Emissões de $\mathrm{CO}_{2}$ : Uma Análise do Setor de Transportes Brasileiro. In: ENCONTRO NACIONAL DE ECONOMIA, 39., 2011, Foz do Iguaçu. Anais... Foz do Iguaçu: ANPEC, 2011.

ANTAQ, A. N. DE T. A. Hidrovias Brasileiras, Indicadores do Transporte de cargas: tonelada útil (t)ve tonelada kilometro útil (TKU). Brasília: [s.n.].

ANTAQ, A. N. DE T. A. TKU da navegação interior e de cabotagem - 2014. Brasília: Agencia Nacional de Transportes Aquaviários - ANTAQ, 2015. Disponível em: <http://www.antaq.gov.br/portal/pdf/EstatisticaNavinterior/Transporte_de_Cargas_Hi drovias_Brasileiras_2015TKU.pdf>.

COSTA, Luiz Sergio Silveira. As Hidrovias Interiores no Brasil. $2^{\circ}$ edição, Editora Femar, 2001.

CHOLLEY, A. Observações sobre alguns pontos De vista geográficos. Brasil: Instituto Brasileiro de Geografia e Estatística - IBGE, 1964. Disponível em: <http://geografiaeconomicaesocial.ufsc.br/files/2016/04/Boletim_Geografico_1964_v 22_n180_-_texto_CHOLLEY_2.pdf>.

DHSP. Carga Transportada na Hidrovia Tietê-Paraná. Disponível em: <http://www.dh.sp.gov.br/carga-transportada/>. Acesso em: 22 nov. 2016.

FREITAS, M.J., REIS, G.M., TOLOI, R.C., VENDRAMENTO, O., Waterways Cargo Transportation: A Comparison between Brazil and the United States, 6o.ILS, BORDEAUX, FRANCE, 2016

FELIPE JUNIOR, N. F.; SILVEIRA, M. R. A Hidrovia Tietê-Paraná e o Porto Intermodal de Pederneiras-SP: Transporte de Cargas e Participação do Capital Privado. Geosul, v. 24, n. 47, 2009. 
JOÃO, M. M., \& JOÃO, D. M. Transportes e Emissões de CO2: Uma Abordagem Baseada na Metodologia do IPCC. INGEPRO, pp. 109-118, 2008.

Ministério dos Transportes - MT. Banco de Informações e Mapas de Transporte - BIT. Disponível em: <http://www.transportes.gov.br/bit/hidro/hidro.htm>. Acesso em: 21 de nov. 2016.

OMETTO, J. G. S. Os gargalos da agroindústria. O Estado de São Paulo, p. B2, 22 maio 2006.

OLIVA, José Alex Bôtelho de. Panorama das Hidrovias Brasileiras. Disponível em: <http://www.antaq.gov.br/portal/pdf/Palestras/SeminarioBrasilHolanda/04Marco/Pale straAlexOlivaBrasilHolanda.pdf>. Acesso em: 21 nov. de 2016.

PERRUPATO, M. Seminário Internacional de Hidrovias Brasil-Holanda. Brasília: MINISTÉRIO DOS TRANSPORTES, 2009.

POMPERMAYER, F. M.; CAMPOS NETO, C. A. S.; DE PAULA, J. M. P. Hidrovias no Brasil: perspectiva histórica, custos e institucionalidade. Rio de Janeiro - RJ: IPEA, 2014.

RAMOS, Samantha Avance Pereira; CARDOSO, Patrícia Alcântara; CRUZ, Marta Monteiro da Costa. Atributos Considerados sobre Sustentabilidade no Transporte Rodoviário de Carga. Anais.. do XXVIII Congresso de Pesquisa e Ensino em Transporte, ANPET, Curitiba, v.1, 2014.

REIS, J.G.M. dos, Toloi, R.C., Freitas, M.F., Análise da Viabilidade do Transporte de Soja de Mato Grosso via Hidrovia Tietê-Paraná,1ํㅡㄹ Einepro, São João da Barra-RJ, 2015. 
SANTOS, B. Rios de oportunidades. Disponível em:

$<$ http://dinheirorural.com.br/secao/agronegocios/rios-de-oportunidades>. Acesso em: 22 nov. 2016.

TEIXEIRA, Paulo Eduardo Ferlini. Desempenho de Terminais Hidroviários do Corredor Logístico Centro-Oeste: Um Estudo de Multicasos. Dissertação de Mestrado. Campo Grande: UFMS, 2010.

TOKARSKI, Adalberto. Hidrovias Brasileiras. Disponível em: $<$ http://www.antaq.gov.br/portal/pdf/palestras/Mar0722PalestraENEPHAdalberto.pdf> Acesso em: 21 nov. de 2016

TOLOI, R. C. et al. Confronto da Competitividade da Soja de Mato Grosso e de Illinois nos Estados Unidos. Anais... do XXXVI Encontro Nacional de Engenharia de Produção, ENEGEP, João Pessoa, 2016. 